\title{
Surgical Assessment of Diffuse Pigmented Villonodular Synovitis
}

\section{Diffüz Pigmente Villonodüler Sinovite Cerrahi Yaklaşım}

\author{
Güray Toğral, Murat Arıkan, Meftun Karataş, Erdem Aktaş, Şafak Güngör \\ Dr. A. Y. Ankara Onkoloji Eğitim Ve Araştırma Hastanesi, Ortopedi Ve Travmatoloji Kliniği, Ankara, Türkiye
}

\section{ÖZET}

Amaç: Diz ekleminde diffüz pigmente villonodüler sinovit tanısı alan biri bilateral 16 olgu klinik, histopatolojik bulgular ve cerrahi tedavi sonuçları açısından incelenmiştir.

Yöntemler: Diffüz pigmente villonodüler sinovit (DPVNS) tanısı alan 16 olgunun 4 yıllık takip sonuçları retrospektif olarak incelenmiştir. Yaş aralığı 16 ile 44 (ortalama 30) olan hastaların 10'u erkek, 6'sı kadındı. 9 hastada sol, 7 hastada sağ diz eklem tutulumu mevcuttu. Ağrı, şişlik ve kitle etkisi ile oluşan bası semptomları varlığı en sık görülen semptomlard1.

Bulgular: Fizik muayenede en sık bulgu (\%40) özellikle suprapatellar bölgede görülen şişlik idi. Hastaların $\% 95$ 'inde klinik olarak diz ekleminde efüzyon mevcuttu. Hastaların 11'inde ortalama $1.5 \mathrm{~cm}$ olarak ölçülen uyluk atrofisi vardı. Oniki hastada ise tutulan eklemde 10 dereceye varan fleksiyon kontraktürü mevcuttu. 8 hastaya başvuru öncesi tanı amaçlı diz eklem içi aspirasyon yapılmıştı ve sadece 3 hastada aspirasyonda karakteristik sero-hemorojik sıvı içeriği gözlendi.

Sonuç: Biz DPVNS'de hastaların tanısında fizik muayene bulguları ve anamnezlerinin çok önemli olduğunu düşünmekteyiz. Ayrıca bu hastalarda öncelikli olarak hastalığın akla getirilmesi ve ön planda artrosenteze başvurulmaması gerektiği kanısındayız. PVNS'nin hala günümüzde primer tedavisi açık veya artroskopik olarak yapılan sinovyektomidir.

Anahtar Kelimeler: Pigmente villonodüler sinovit; Hemorajik efüzyon; Diz; Sinovyal membran

\begin{abstract}
Objectıve: One bilateral totally 16 diffuse pigmented villonodular synovitis of the knee cases was examined in terms of clinical presentations, histopathological findings and surgical outcome.

Methods: 16 patients with the diagnosis of DPVNS were retrospectively analyzed with a period of 4 years. The mean age was 30 years (16-44). 10 patients were male and 6 patients were female. Nine patients left and 7 patients right knees were affected. Pain, swelling and pressure symptoms caused by mass effect were the most common clinical findings.

Results: The most common physical examination finding was suprapatellar swelling (40\%). Effusion in the knee joint was detected in $95 \%$ of the patients. There was mean of $1.5 \mathrm{~cm}$ thigh atrophy in 11 patients. Flexion contracture about 10 degrees in the affected knee was noted in 12 patients. Three of 8 patients that knee aspiration was performed have characteristic sero-hemorrhagic fluid.

Conclusion: We think that physical examination and history is very important in diagnosis of patients with PVNS. Aspiration of the joint should be avoided. Open or arthroscopic syneviectomy is the primary treatment of PVNS.
\end{abstract}

Key words: Pigmented villonodular synovitis; Hemorrhagic effusion; Knee; Synovial membrane

\section{Giriş}

Pigmente villonodüler sinovit (PVNS) sinovyal dokunun nedeni bilinmeyen, benign, proliferatif, inflamatuar bir hastalığıdır. İlk kez 1941 yılında Jaffe tarafından tanımlanmıştır. Lokalize ve yaygin olmak üzere iki formu vardır (1). Lokalize form; sinovyal dokunun nodüllerle karakterize fokal proliferasyonu şeklindedir. Yaygın formda ise eklemdeki bütün sinovyal doku tutulmuştur $(1,2)$. İnsidans1 2/1.000.000'dir (1,2). PVNS, her yaş grubunda görülebilmekle birlikte, en s1k görüldüğü yaş aralığı 20-50'dir. Kadın-erkek oranı eşittir. Hastalar en sik ilgili ekstremitede ağrı ve şişlik şikayetleri ile hastaneye başvururlar. Diz ekleminde sik tekrarlayan effüzyon atakları olabilir. Eklem ponk- 
siyonunda normalden daha koyu sarıdan kırmızı kahverengiye kadar değişen özellikte s1v1 aspire edilmesi halinde mutlaka PVNS'den şüphe edilmelidir (3).

Hastalığın histolojik bulguları ile doğal geçmişi arasındaki ilişki belirsizdir. Radyolojik bulguların hastalığın klinik davranışını belirlemede etkinliği halen tartışmalıdır. Genellikle tek bir eklemi tutar. Vakaların sadece \%1'inde bilateral diz eklem tutulumu görülür (4). En s1k diz eklemi olmak üzere, tüm sinovyal doku içeren eklemlerde görülebilir. Tendon kılıfı, fasya, bursa gibi eklem dişı yapıların sinovyalarından da köken alabilir $(5,6)$.

Direkt radyografilerde ilgili ekstemite çevresindeki yumuşak doku dansitesinde bir artış görülür. Hastalığın derecesine göre tutulan eklemde, kemik yapıda dejeneratif değişiklikler, subkondral kistler izlenebilir (Resim 3). Kalsifikasyon gözlenmez. Bilgisa-
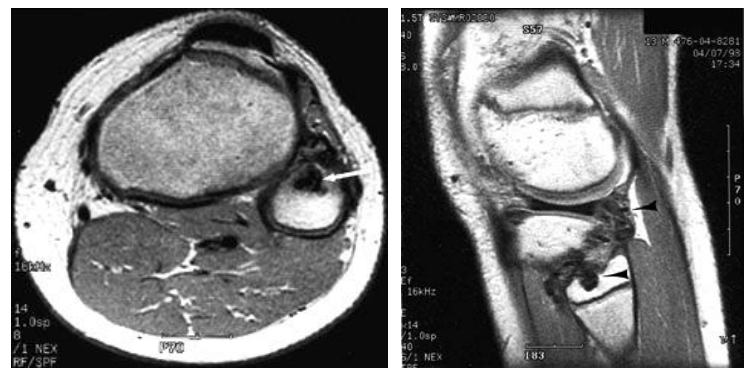

Resim 1: Diz posterolateral yerleşimli PVNS'li bir hastanın T1 ağırlıklı MRI görüntüsü. yarlı tomografi; özellikle kemik erozyonlarını ve derecesini saptamada faydalı bir görüntüleme yöntemidir. MR, PVNS tanıs1 koyma ve ayırıcı tanıya gitmede büyük kolaylık sağlamıştır. MR ile nodül içeriğinde hemosiderin artışı ile düşük sinyal intensitesi, yağ artışı ile ise yüksek sinyal intensitesi saptanır (Resim 1) $(7,8)$.

PVNS tedavisi; eklemdeki hasarın derecesi ve hastanın yaşına göre değişir. Belirgin eklem hasarı ve kemik erozyonu olmayan hastalarda total sinovektomi en seçkin tedavi yöntemidir (9). Açık veya artroskopik yöntemlerle yapılabilir (Resim 4). Total eksizyon yapilamayan durumlarda ameliyat sonrasi ek olarak radyoterapiden yararlanılabilir. Hastalığın ileri evrelerinde artroplasti veya artrodez uygulanabilen diğer cerrahi tedavi seçenekleridir.

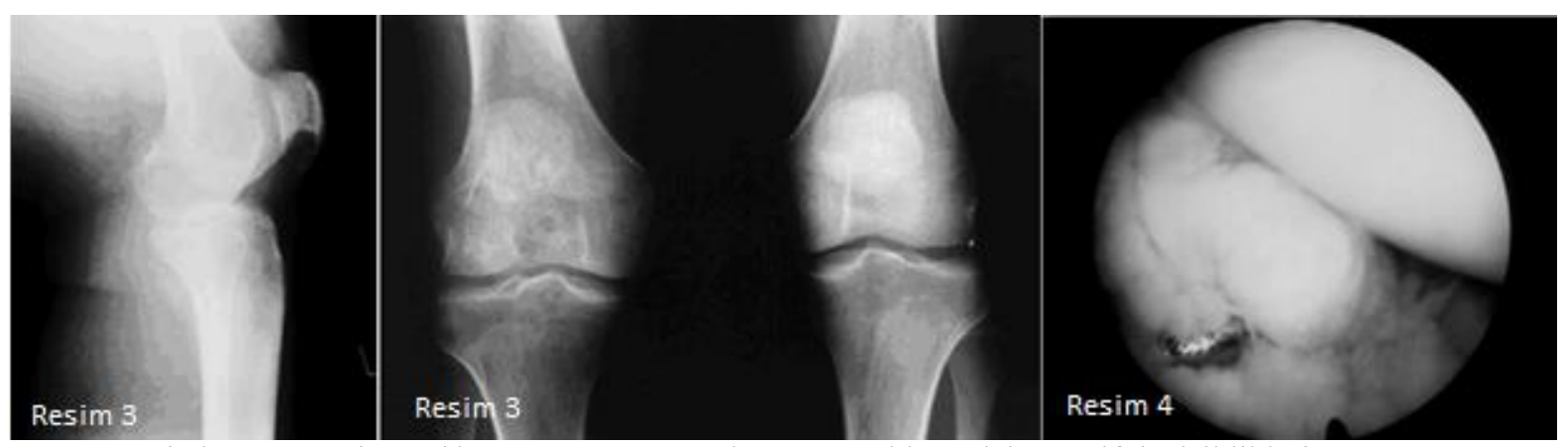

Resim 3: Dizde PVNS'nin AP/ lateral direk X-ray’de yapmış olduğu dejeneratif değişikliklerin görünümü, 4: PVNS'li hastada artroskopik olarak diz eklem içi görünümü

\section{Klinik}

Gerçekte PVNS klinik olarak diğer hastalıkları taklit edebilmektedir. Hastalarımızda en sik konulan yanlış tanı ekstensör mekanizma bozukluğudur (Tablo 1).
Semptomlar ani başlangıç ve progresyon sonucu gelişen diz eklem şişliği ile karakterizedir. Hastaların 1/3'ünde travma öyküsü vardır. Tüm hastalar ilgili eklemde şişlik, ve şişlikle alakalı ağrı yakınmalarından dolayı hekime başvurur. Ekstensör mekanizma disfonksiyonunu taklit eden sertlik PVNS'nin 
diğer karakteristik semptomları ile zitlık göstermektedir.

Tablo 1:Hastaların preoperatif tanıları

\begin{tabular}{|l|c|}
\hline Tanı & Sayı \\
\hline Menüsküse ait lezyon & 3 \\
\hline İnflamatuvar artrit & 2 \\
\hline Ligamentte instabilite & 1 \\
\hline Popliteal kist & 1 \\
\hline Plika sendromu & 1 \\
\hline Osteoartrit & 1 \\
\hline Myozit & 1 \\
\hline Ekstensor mekanizma bozukluğu & 5 \\
\hline
\end{tabular}

\section{Gereç ve Yöntemler}

Diffüz PVNS tanıs1 alan ve bir tanesi bilateral olan 16 olgunun 4 y1llık tedavi süreci retrospektif olarak incelenmiştir. Yaşları 16 ile 44 aras1 (ortalama 30) olan hastaların 10'u erkek, 6'sı kadındı. Romatizmal hastalığı olan bir hasta dışında hiçbirinde ek bir hastalık yoktu. Hastaların 8'ine klinik, görüntüleme yöntemleri ve eklem ponksiyonu sonuçları ile tanı kondu. Diğer 7'sine ise operasyon sirasinda yapılan frozen biyopsi ile tanı kondu. Sekiz hastada sol, 6 hastada sağ ve bir hastada bilateral diz eklem tutulumu vard1. Sol diz tutulumu olan 7 hastanın 2'sinde ve sağ diz tutulumu olan 6 hastanın birinde poliartiküler tutulum görülmüştür.

Hastaların tüm medikal kayıtları, epikrizleri, ameliyat raporları ve patoloji sonuçları incelenmiştir. Bu hastaların tamamı artrotomi ile sinovyektomi yapılarak tedavi edilmiştir. Hepsinin histolojik tanıları PVNS ile uyumlu olarak gelmiştir.

\section{Bulgular}

Yaş, cinsiyet, etkilenen diz eklemi, eşlik eden artrit ve eklem tutulumu varlığı gibi demogratif bulgular kayıt altına alınmıştır. Klinik muayene bulguları, dizdeki fleksiyon ve ekstansiyon kisitlılık dereceleri, ilgili eklemde uyluk atrofisi ve kuadriseps tonusu gücü, eklem şişliği kayıt altına alınan diğer bulgulardır.

Fizik muayenede en sik bulgu suprapatellar şişliktir. Efüzyon hastaların \%95'inde görülmüştür. Hastaların \%40'ında suprapatellar bölgede muayenede ele gelen diffüz sinovyal kitle mevcuttu. Hastaların 11'inde tutulum görülen ilgili ekstremitede ortalama $1.5 \mathrm{~cm}$ uyluk atrofisi mevcuttu. Oniki hastada 10 derece varan eklem fleksiyon kontraktürü vardı.

Yedi hastaya başvuru öncesi tanı amaçlı diz eklem içi aspirasyon yapıldı. Sadece 3 hastada aspirasyonda karakteristik hemorajik sıv1 içeriği gözlendi. Aspirasyon negatif olan kalan 4 hastada tanı klinik muayene ve görüntüleme tetkikleri incelenerek konuldu. Geri kalan 8 hastanın tanis1 operasyon sirasında alınan frozen biyopsi ile kondu.

Tüm hastaların tanıları post operatif patoloji sonuçları ile doğrulanmıştır (Resim 2). Raporlarda çıkartılan dokudaki kalsifikasyon ve kıkırdak varlığ 1 detaylı incelenmiştir. Ameliyat notları incelenerek artrotomi sırasında görülen sıvının rengi ve karakteri hakkında da bilgi kayıt altına alınmıştır.

Hastaların patolojileri Myers ve ark.'nın daha önce yaptığ 1 histolojik derecelendirmeye göre sinıflandırılmıştır (2). Grad 1 erken granülasyon dokusu ve stromal hücreler, grad 2 mikst stromal hücreler ve fibröz doku, grad 3 hyalinizasyon ile birlikte geç fibröz doku olarak ifade edilir. Histolojik grad ile rekürrens oranı ve hastalığın şiddeti derecelendirilmeye çalış1lıp, histolojik görüntünün prognoz üzerindeki belirleyiciliği karşılaştırılmıştır (1). Bu çalışmadaki 16 hastanın 5'i grad 1, 8'i grad 2, 2'si grad 3 tanısı aldi.

Hastalar artrotomi ile yapilan total sinovyektomi ile tedavi edilmiştir. Rekürrens zamanı ameliyattan sonra PVNS'nin yol açtığı karakteristik klinik semptomlarının yeniden ortaya çıktığ 1 , klinik ve radyolojik olarak tanı konulan zamandır. Hastaların \%56'sında aspirasyon veya artrotomi sonrasinda elde edilen eklem sivisının rengi tanı ile uyumsuzdu.

Semptomların başlangıcından tanıya kadar geçen sürenin uzunluğu ile fibrozisin yaygınlığı arasında bir ilişki bulunamamıştır. İnflamasyon lezyonların 2/3'ünde, dev hücre varlığı hastaların yarısından fazlasında gözlenmiştir.

\section{Tartışma}

Çoğunlukla genç erişkinlerde olmak üzere, 3040 'lı yaşlarda en fazla görülen, cinsiyet fark1 
gözetmeyen, nadir görülen bir hastalık olan PVNS'nin etyolojisi halen belirsizdir. Diffüz PVNS patogenez ve tanısal özelliği hastalığın seyrek görülmesi nedeni ile zordur. Çoğu araştırmacının ortak düşüncesi, bu durumun bilinmeyen bir uyarana karşı gelişen enflamatuar bir yanıt olduğu yönündedir.

PVNS'de diz eklemi tutulumu çok sayıdaki yayında gösterilmiştir. PVNS'de suprapatellar poşta geniş miktarda sıvı birikmesi, lezyonun invazyon etkisi ile olduğunu düşündürmektedir. Klinik olarak PVNS, çevre yumuşak doku ve/veya kemiği tutan lokal agresif iyi huylu neoplazi gibi davranır $(7,8)$. Hastalar da bir kez sinovit saptandığında tanı koymak kolaylaşır. Hastalar genellikle sedanter yaşayan genç yetişkin bireylerdir. Semptomlar zamanla ilerler. Hastalığın travma veya aktivite ile ilişkili olduğu düşünülmektedir $(8,9)$.

Semptomların başlaması ile hastalığın tanısının konduğu ana kadar geçen süre oldukça uzundur. Schwartz ve ark. bu süreyi ortalama 4 yıl olarak bildirmişlerdir(10).

Hastaların genelikle semptomları ilgili ekstremite de şişlik ve şişliğin neden olduğu bas1 semptomlarıdır. Belirgin efüzyonun neden olduğu şişlik genellikle birliktedir. Bu kronik gerginlik kendini sıklıkla ekstensör mekanizma bozukluğu olarak gösterir ve kronik rekürren semptomlarla devam eder (11).

PVNS'de kemik değişikliklerinin ve subkondral bölgedeki kistlerin oluş mekanizmaları çeşitli teorilerle açıklanmaya çalışılmıştır. Chung ve Janes, sinovyal proliferasyon nedeniyle artan eklem içi basincin lokal osteoporoz ile kortikal defektlere neden olduğunu söylemiștir (12). Scott ise sinovyal dokunun vasküler foraminalar içinden girerek kemiği penetre ettiğini ileri sürmüştür. Henüz bu konu açıklığa tam olarak kavuşmamıştır. PVNS; sinsi başlangıçlı, ilerleyici vasıfta, genellikle tek eklemi tutan, bir orta yaş hastalığıdır. Nadiren çocuk ve ileri yaşlarda da görülebilir. Olguların dörtte üçünde diz eklemi tutulur. Sonra sırasıyla kalça, ayak bileği, omuz ve dirsek eklemi tutulumları görülür.

Bizim çalışmamızda 16 olgunun 6'sında tan1, ameliyat öncesi hastaların semptomları fizik muayene ve görüntüleme tetkiklerinin birlikte değerlendirilmesi ile mümkün olmuştur. Fizik muayenede dizin fleksiyonunda kısmi kısıtlılık ön planda idi.
Şişliğin en sık patellafemoral ekleme yakın olduğu görüldü. Uyluk atrofisi çoğu hastada ölçülebilir düzeydeydi. Tüm olgularda efüzyon mevcuttu. Van Meter ve Rowdon kilitlenmiş bir dizde menüsküs kova sap1 yırtığını taklit eden lokalize bir PVNS olgusu (13); Williams, Myers ve ark. hoffa yağ yastıkçı̆̆ından köken alan ve dizin kilitlenmesine yol açan iki olgu, Bronstein ve arkadaşları ise yine dizde kilitlenmeye yol açan ve ameliyat öncesinde eklem faresi tanisi alan ve artroskopi sirasinda lokalize PVNS olduğu anlaşılan bir olgu bildirmişlerdir $(2,14)$.

$\mathrm{Bu}$ hastalığın tedavisi hala günümüzde artroskopik veya açı total sinovyektomidir. $\mathrm{Bu}$ hastalığın tanısında ve tedavi yönetimi konusunda daha geniş çapta araştırmalara ihtiyaç vardır.

\section{Çıkar Çatışması: Yok}

\section{Kaynaklar}

1. Jaffe HL, Lichtenstein L, Sutro CJ. Pigmented villonodular synovitis. bursitis and tenosynovitis: Arch. Pathol 1941;31:731-65

2. Myers BW, Masi AT. Pigmented villonodular synovitis and tenosynovitis: A clinical epidemiologic study of 166 cases and literature review. Medicine (Baltimore) 1980;59:223-38

3. Kay RM, Eckardt JJ, Mirra MM. Multifocal Pigmented Villonodular Synovitis in a Child. Clin Orthop 1996;322:194-7

4. Klammer G, Betz M, Delaloye B, Farshad M, Peter KP. Bilateral diffuse pigmented villonodular synovitis of the knee. J Knee Surg. 2013;26 Suppl 1:S67-71

5. Ma X, Shi G, Xia C, Liu H, He J, Jin W. Pigmented villonodular synovitis: a retrospective study of seventy five cases (eighty one joints). Int Orthop 2013;37:1165-70

6. Byers PD, Cotten RE, Deacon OW, et al. The diagnosis and treatment of pigmented villonodular synovitis. J Bone Joint Surg 1968;50:290-3

7. Jobe CM, Raza A, Zuckerman L. Pigmented villonodular synovitis: extrasynovial recurrence. Arthroscopy 2011;27:1449-51

8. Vigorita VJ: Pigmented villonodular synovitislike lesions in association with rare cases of rheumatoid arthritis, osteonecrosis. and advanced degenerative joint disease. Report of five cases. Clin Orthop 1984;183:1-15

9. Palumbo RC, Matthews LS, Reuben JM. Localized pigmented villonodular synovitis of the patellar fat pad: a report of two cases. Arthroscopy 1994;10:4003

10. Schwartz HS1, Unni KK, Pritchard DJ. Pigmented villonodular synovitis. A retrospective review of affected large joints. Clin Orthop Relat Res 1989;247:243-55 


\section{Original Article}

11. Verspoor FG, Zee AA, Hannink G, van der Geest IC, Veth RP, Schreuder HW. Long-term follow-up results of primary and recurrent pigmented villonodular synovitis. Rheumatology (Oxford). 2014;53:2063-70

12. Chung SMK, Janes JM. Diffuse pigmented villonodular synovitis of the hip. Revievv of the literatüre and report of four cases. J Bone Joint Surg 1965;47:293-303
13. Van Meter CD, Rowdon GA. Localized pigmented villonodular synovitis presenting as a locked lateral meniscal bucket handle tear: a case report and review of the literature. Arthroscopy 1994;10:309-12

14. Bronstein RD, Sebastianelli WJ, DeHaven KE. Localized pigmented villonodular synovitis presenting as a loose body in the knee. Arthroscopy 1993;9:596-8 